\title{
Molecular Homology and Incompatibility Relationships between $F$ and IncH1 Plasmids
}

\author{
By DIANE E. TAYLOR, ${ }^{1}$ R. W. HEDGES ${ }^{2}$ AND P. L. BERGQUIST ${ }^{3 *}$ \\ $'$ Department of Medical Microbiology, University of Alberta, Edmonton, Alberta, \\ Canada T6G $2 \mathrm{H7}$ \\ 2 Laboratorium voor Genetica, Rijksuniversiteit Gent, Gent, Belgium \\ ${ }^{3}$ Department of Cell Biology, University of Auckland, Auckland, New Zealand
}

(Received 2 January 1985)

\begin{abstract}
IncH1 plasmids and the $\mathrm{F}$ plasmid of Escherichia coli display one-way compatibility. An entering IncH 1 plasmid is incompatible with a resident $\mathrm{F}$ plasmid, but is compatible when it is the resident plasmid. There is little molecular homology between IncH1 plasmids and the F plasmid. A single $5 \mathrm{MDal}$ EcoRI restriction enzyme fragment from digests of several IncHl plasmids hybridizes with probes constructed from the primary replication region of $F$. Homology can be demonstrated only with the gene for the essential replication protein of $F$ (gene E), but the expression of incompatibility behaviour appears to be associated with the presence of the secondary replicon of the F plasmid. Thus R27 and F are compatible under growth conditions allowing replication and maintenance of $\mathrm{F}$ by the secondary replicon. However, a mutant $F$ plasmid which lacks the secondary replicon of $F$ is incompatible with R27 in both directions, irrespective of the growth conditions used.
\end{abstract}

\section{INTRODUCTION}

Smith et al. (1973) demonstrated one-way incompatibility between the F plasmid and plasmids of the IncH 1 group. They showed that when an IncH 1 plasmid entered a cell carrying $F$ as the resident plasmid, the latter segregated. However, when $F$ entered a cell carrying an IncH 1 plasmid, the two plasmids were compatible. In some cases, segregants of IncH 1 plasmids which had lost resistance to tetracycline also lost their one-way incompatibility with $F$ : the two plasmids were compatible irrespective of which plasmid was used as the donor.

In general, it has been shown that closely related plasmids of the same incompatibility group exhibit significant homology, as judged by DNA-DNA hybridization (Falkow et al., 1974). However, it has also been shown that there is little homology between $\mathrm{F}$ and four IncHl plasmids (Smith et al., 1973; Roussel \& Chabbert, 1978). The incompatibility relationship observed for $\mathrm{F}$ and $\mathrm{IncH} 1$ plasmids could be explained if the homology resided in a replication region (replicon) shared by the two plasmid groups.

We showed that incompatible IncFI plasmids share regions of specific DNA homology that are able to express incompatibility. Individual IncFI plasmids possessed combinations of these loci and we suggested that the presence of multiple inc determinants on a single plasmid may lead to cross-reactions between members of different incompatibility groups (Lane, 1981; Bergquist et al., 1982). We examined the DNA homology between the F plasmid and several plasmids of the IncH 1 group by hybridization of radioactive fragments of the $\mathrm{F}$ incompatibility regions to restriction enzyme digests of the $\mathrm{IncH} 1$ plasmids. The aims of this investigation were to examine the extent of molecular homology between the F plasmid and $\mathrm{IncH} 1$ plasmids and to establish if this homology could be related to the observed incompatibility behaviour of the plasmids. 
Table 1. Plasmids

\section{Plasmid}

$\begin{array}{ll}\text { R27 } & \text { Tc } \\ \text { R726 } & \text { TcCmSmSu } \\ \text { R726-1 } & \text { CmSmSu } \\ \text { pIP166 } & \text { TcCmSmSu } \\ \text { TP123 } & \text { TcCmSmSu } \\ \text { pIP522 } & \text { CmSmSu } \\ \text { TP116 } & \text { CmSmSu } \\ \text { pNZ130 } & \text { SmSu } \\ \text { F and F'-lac } & -; \text { Lac }^{+} \\ \text {F::Tn9 } & \text { Cm } \\ \text { F( }(\Delta 33-43):: T n 9 & \mathrm{Cm}\end{array}$

Inc

group

$\mathrm{H} 1$

$\mathrm{H} 1$

$\mathrm{Hl}$

H1

$\mathrm{H} 1$

$\mathrm{H} 2$

$\mathrm{H} 2$

FI

FI

FI

\begin{tabular}{ll}
\multicolumn{1}{c}{ Source } & \multicolumn{1}{c}{ References } \\
N. Datta & Grindley et al. (1972) \\
N. Datta & Datta \& Olarte (1974) \\
N. Datta & Chabbert \& Gerbaud (1974) \\
Y. Chabbert & Grindley et al. (1972) \\
N. Datta & Chabbert \& Gerbaud (1974) \\
Y. Chabbert & Grindley et al. (1972) \\
N. Datta & Watson et al. (1982) \\
L. Watson & Bergquist et al. (1982) \\
P. L. Bergquist & This paper \\
P. L. Bergquist & This paper
\end{tabular}

* Abbreviations: Tc, tetracycline resistance; $\mathrm{Cm}$, chloramphenicol resistance; $\mathrm{Sm}$, streptomycin resistance; Su, sulphonamide resistance; Lac, lactose.

\section{METHODS}

Plasmids. The plasmids used are listed in Table 1. Plasmid DNA was prepared by a minor modification of the method of Currier \& Nester (1976). EcoRI digests of IncH1 plasmid DNAs were electrophoresed on a $0.7 \%$ acetate agarose gel and were coupled to diazobenzyloxymethyl (DBM) paper together with an EcoRI digest of F. The DBM paper was hybridized with radioactive probes constructed by nick translation of the primary (f5) and secondary $(\mathrm{f} 7$, incE) replicon regions of $\mathrm{F}$ (Bergquist et al., 1982) under conditions that allowed detection of sequences having $20 \%$ base mismatch or less (Hyman et al., 1973).

Molecular probes. The incB sequence and the E gene sequences used as probes were, respectively, 240 and $380 \mathrm{bp}$ fragments that were isolated from $8 \%$ acrylamide gels after digestion of pNZ130 with Sau $3 \mathrm{~A}$ (Watson et al., 1982). The $\mathrm{E}$ gene is located between $\mathrm{F}$ co-ordinates $42 \cdot 251$ and 46.004 . The Sau 3A fragments used are entirely internal to the coding sequence (Murotsu et al., 1981). The incC-E gene sequence was a Pst I-AluI fragment of 470 bp which was isolated from an appropriate digest of pNZ130. This fragment carries $100 \mathrm{bp}$ of the coding sequence for the carboxy-terminal portion of the $\mathrm{E}$ gene as well as the five $19 \mathrm{bp}$ repeated sequences of the inc $\mathrm{C}$ region. There were no suitable restriction enzyme cleavage sites that allowed removal of the $E$ gene sequence from this fragment. Nick translation of these fragments was done by the method of Rigby et al. (1977).

Assessment of homology between the $E$ gene-IncC probe and the EcoRI fragment from IncHI plasmids. An approximation to the relative amount of homology to the probe was obtained by densitometry of the bands that hybridized in the gel and the radioautograph, to correct for the different amounts of DNA present (Fig. 2). Confirmation of the limited amount of homology found in this way was provided by hybridization of the $E$ gene probe at low stringency ( $40 \%$ mismatch) to IncHI and $\mathrm{F}$ plasmid DNAs coupled to DBM paper. The paper was washed under conditions of increasing stringency up to $10 \%$ mismatch, and radioautographed after each wash. The relative amount of radioactivity hybridized remained roughly constant at $20 \%$ mismatch.

Incompatibility. Incompatibility testing was performed using $E$. coli strain $\mathrm{PB} 1150$ ( $\left.\mathrm{His}^{-}, r p o B, r e c A l\right)$ carrying either R27 or one of the F plasmids as the recipient bacterium. In experiments on the effect of growth conditions on segregation of $\mathrm{F}$, incompatibility testing was performed by the method of Gardner et al. (1982) because of the observed segregation of $\mathrm{Lac}^{-}$in colonies on the selective plates. After about 22 generations growth in either $\mathrm{L}$ broth or minimal salts medium plus amino acid supplements, the colonies were spread either to $\mathrm{L}$ plates or to minimal agar plates. The colonies that appeared on these plates were then replicated to suitable broth or minimal plates containing tetracycline plus 5-bromo-4-chloro-3-indolyl $\beta$-D-galactoside (Xgal) and isopropylthio- $\beta$-Dgalactose (IPTG) or lactose for the determination of the presence or absence of the plasmid(s) they carried (see Table 2). Incompatibility testing in experiments with $F(\Delta 33-43)::$ Tn 9 followed the same procedure and the results were confirmed using the maintenance test as described by Bergquist et al. (1982).

\section{RESULTS AND DISCUSSION}

\section{Hybridization of probes}

Preliminary experiments demonstrated that only the f5 fragment (incB, $C, D$ ) showed hybridization to the $5 \mathrm{MDal}$ fragment present in digests of all of the IncH 1 plasmids. Other experiments showed that the only homology between $\mathrm{F}$ and the $\mathrm{IncH} 1$ plasmids resided in this fragment. Probes containing the incB-E gene-inc $C$ region were originally broadly defined by cleavage sites for Pst I at F44.1, 45.88 and $47 \cdot 3 \mathrm{~kb}$ co-ordinates (Bergquist et al., 1982 and Fig. 1). 


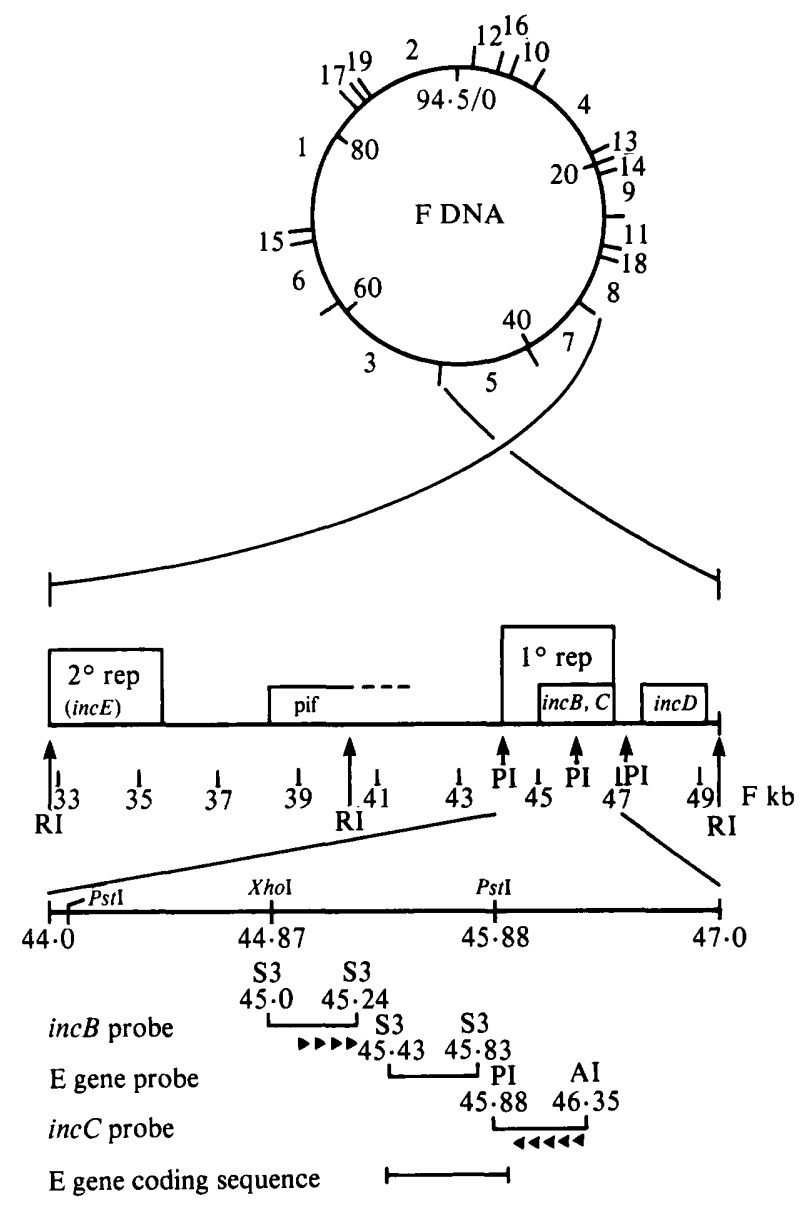

Fig. 1. Restriction map of $F$ showing the replication regions and probes used. The top portion of the figure shows the $E c o$ RI cleavage sites and the fragment numbers of the F plasmid on the outside of the circle; $\mathrm{F} \mathrm{kb}$ co-ordinates are shown on the inside. The replication regions are shown on a larger scale in the middle portions of the figure. The origin and extent of the DNA fragments used for probes are indicated in the lower portion of the figure. Filled triangles indicate the repeat sequences of incB and inc C. Restriction enzyme sites: RI, EcoRI; S3, Sau3A; PI, Pst I AI, AluI. Other abbreviations (see Lane, 1981): pif, interference with phage T7 multiplication; $1^{\circ}$ rep, primary replicon (f5); $2^{\circ}$ rep, secondary replicon (f7). The cloning and isolation of restriction enzyme fragments carrying the inc $B, C$, $D$ and $E$ regions and the DNA sequence of this region have been described (Lovett \& Helinski, 1976; Murotsu et al., 1981; Bergquist et al., 1982).

Probes for both the incB and the inc $C$ regions hybridized to the $5 \mathrm{MDal} E c o \mathrm{RI}$ band found in digests of the IncH plasmid DNAs. The nucleotide sequence of this region revealed that it included two sets of repeated sequences which flanked a gene coding for a protein essential for the replication of miniF (Murotsu et al., 1981; Watson et al., 1982). IncB consisted of four $19 \mathrm{bp}$ repeats in one orientation while inc $C$ had five $19 \mathrm{bp}$ repeats in the opposite orientation. The sequence of the nine repeats is highly conserved (Murotsu et al., 1981).

The 240 bp Sau $3 \mathrm{~A}$ fragment which included the secondary origin of replication and the incB sequence did not hybridize with any fragment from the IncH1 plasmids. A second Sau $3 \mathrm{~A}$ fragment of $380 \mathrm{bp}$, which included most of the gene for the E protein, hybridized to the $5 \mathrm{MDal}$ restriction fragment, as did a $P s t \mathrm{I}-A l u \mathrm{I}$ fragment of $470 \mathrm{bp}$ which includes the portion of the gene coding for the carboxy-terminal fragment of the $\mathrm{E}$ protein and the inc $C$ repeat sequences (Fig. 2). Since the repeated sequences were common to the incB and inc $C$ probes, it appeared 


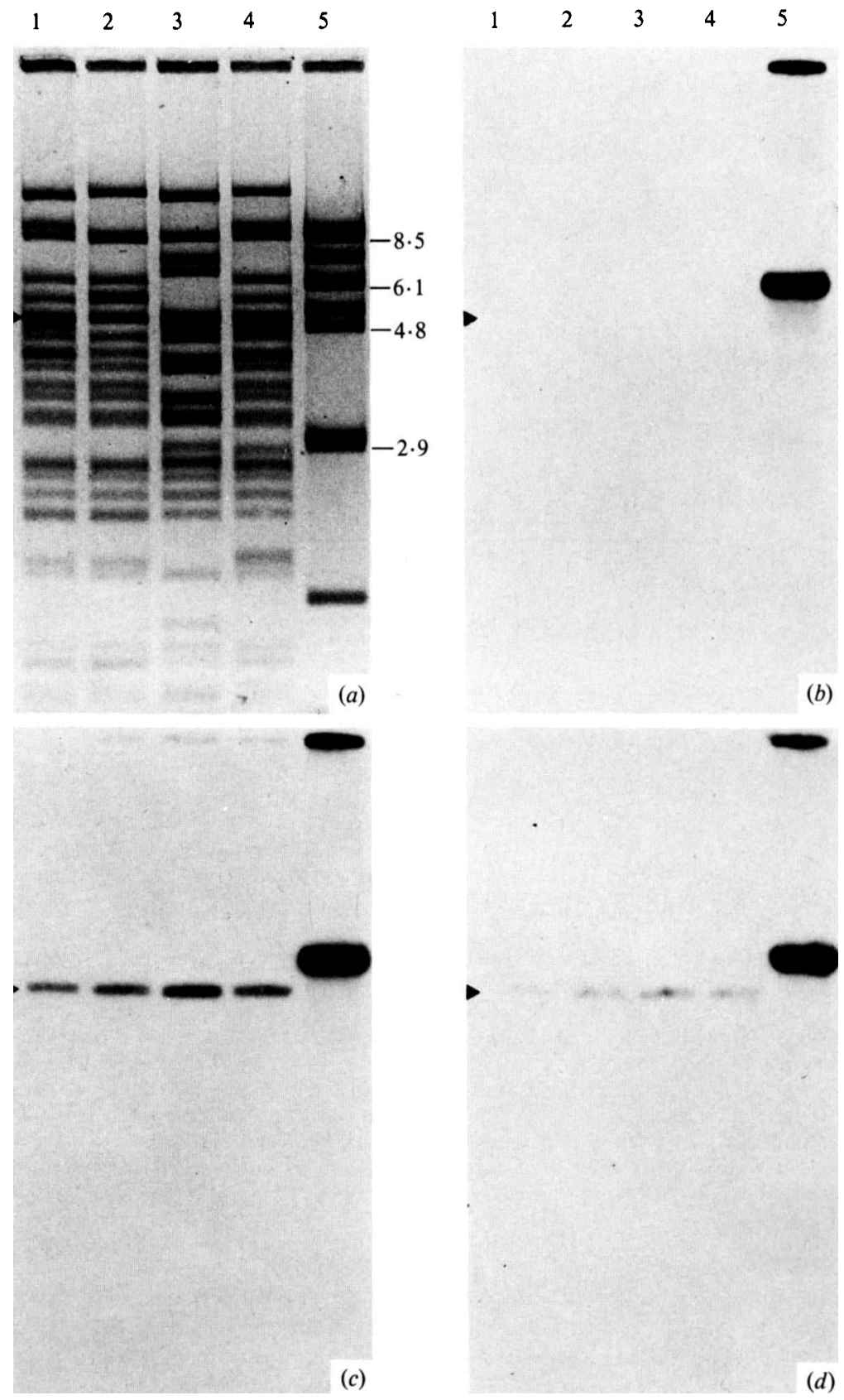

Fig. 2. Hybridization of replication region probes to IncHl and IncFI plasmids. Lanes: $1, \mathrm{R} 726 ; 2$, R726-1; 3, R27; 4, pIP166; 5, F. (a) Ethidium bromide-stained gel; $(b, c, d)$ radioautographs of the DBM paper after hybridization. The position of the $5 \mathrm{MDal}$ fragment of the IncHl plasmids that hybridizes to the $\mathrm{E}$ gene probe is indicated by the arrowheads. Molecular weights (MDal) of some $E c o$ RI fragments of $\mathrm{F}$ are shown to the right of $(a) ;(b)$ inc $B$ probe; $(c) \mathrm{E}$ gene-inc $C$ probe; $(d)$ inc $C$ probe. 
likely that the hybridization of the inc $C$ probe to the $5 \mathrm{MDal}$ fragment represents homology with the coding sequences for the $E$ protein. A less likely possibility was that the homology shown by $\mathrm{R} 27$ was with the $\mathrm{F}$ spacer sequences between the $19 \mathrm{bp}$ repeats of the inc $C$ probe.

The extent of hybridization of the E gene-incC probe to the $5 \mathrm{MDal} E c o \mathrm{RI}$ fragment of the IncH 1 plasmids was approximately $20 \%$ of the value for the $\mathrm{f} 5$ fragment of $\mathrm{F}$. This result suggests that there may be only limited homology between the $E$ gene sequence of the $F$ plasmid and the analogous sequence in the IncH 1 plasmids.

In separate experiments we examined the hybridization of the inc $B, \mathrm{E}$ gene and inc $C$ probes to restriction enzyme digests of the plasmids TP123 (displaces F), TP116 (compatible with F) and pIP522. The latter plasmid is a tetracycline-sensitive segregant of pIP166 (Chabbert \& Gerbaud, 1974). The E gene probe did not hybridize to any EcoRI fragment of either TP116 or pIP522 but hybridized to a 5 MDal fragment of TP123 (data not shown). TP116 is classified as an IncH 2 plasmid on the basis of its compatibility with $\mathrm{F}$ and thus absence of hybridization was in accordance with these results.

Smith et al. (1973) first described tetracycline-sensitive segregants of TP124 which were compatible with F, unlike the parental plasmid. pIP522, a tetracycline-sensitive segregant of the IncH1 plasmid pIP166, showed the same phenotypic behaviour in incompatibility tests (data not shown). In addition, the $5 \mathrm{MDal}$ restriction enzyme fragment of the parental plasmid that hybridized with the E gene probe was lost in the segregant. However, with other plasmid segregants that were tetracycline-sensitive there was no obligatory loss of the restriction enzyme fragment that hybridized to the E gene probe. For example, R726-1 is a tetracycline-sensitive segregant of R726 (Datta \& Olarte, 1974) that retained its homology with F and was incompatible with $\mathrm{F}$ as an entering plasmid (see Fig. 2, incompatibility data not shown). In addition, Taylor (1983) has shown that tetracycline-sensitive derivatives of R27 resulting from transposition of $\mathrm{Tn} 7$ still retained their incompatibility with the $\mathrm{F}$ factor.

\section{Incompatibility between $F$ and $R 27$}

What is the explanation for the one-way incompatibility shown by $\mathrm{F}$ and $\mathrm{IncH} \mathrm{H}$ plasmids? We examined the possibility that it was related to the presence of two functional replicons in $F$ (Lane \& Gardner, 1979), so that this plasmid was able to replicate from either its primary (f5) or secondary (f7) replicon. The deletion mutant $F(\Delta 33-43)$ lacked the f7 region (Anthony et al., $1974)$ and it is assumed to replicate only from the primary replicon. Thus $F(\Delta 33-43)$ should be incompatible with $R 27$ if this plasmid interferes with replication from the primary replicon of $F$. This suggestion was tested in the following way. The secondary replicon of $F$ is partially defective and cannot support efficient replication of $F$ at fast growth rates (Lane \& Gardner, 1979; Gardner et al., 1980). When $\mathrm{F}^{\prime}$-lac ${ }^{+}$was present as the resident plasmid in incompatibility tests with R27, the $\mathrm{Lac}^{+}$character could be seen to segregate if the transconjugants were plated on enriched medium containing lactose and an indicator dye. After non-selective growth for approximately 40 generations in broth medium, few cells contained the resident plasmid (Table 2). On the other hand, if the initial plating of the transconjugants was onto minimal medium with the appropriate supplements and Xgal plus IPTG, segregation was not observed on the plate and most cells contained both the resident and the entering plasmid on testing after nonselective growth (Table 2).

The results in Table 2 suggested that the incompatibility function of the IncH1 plasmid is expressed when it enters a cell containing a resident $F$ plasmid, and that it shuts off replication from the primary replicon of $F$. Replication of the F plasmid is then assumed by the secondary replicon of $F$, which can support plasmid replication best at low growth rates. If this assumption is correct, the deletion mutant $F(\Delta 33-43)$ would be expected to be incompatible with $R 27$ in either broth or minimal medium.

The results of similar experiments to those in Table 2 with a chloramphenicol-resistant derivative of $F(\Delta 33-43)$ were unexpected since only the selected plasmid was maintained (Table 2), although it should be noted that the segregation test used favours situations in which the plasmids tested are weakly incompatible (discussed in Bergquist et al., 1982; Gardner et al., 


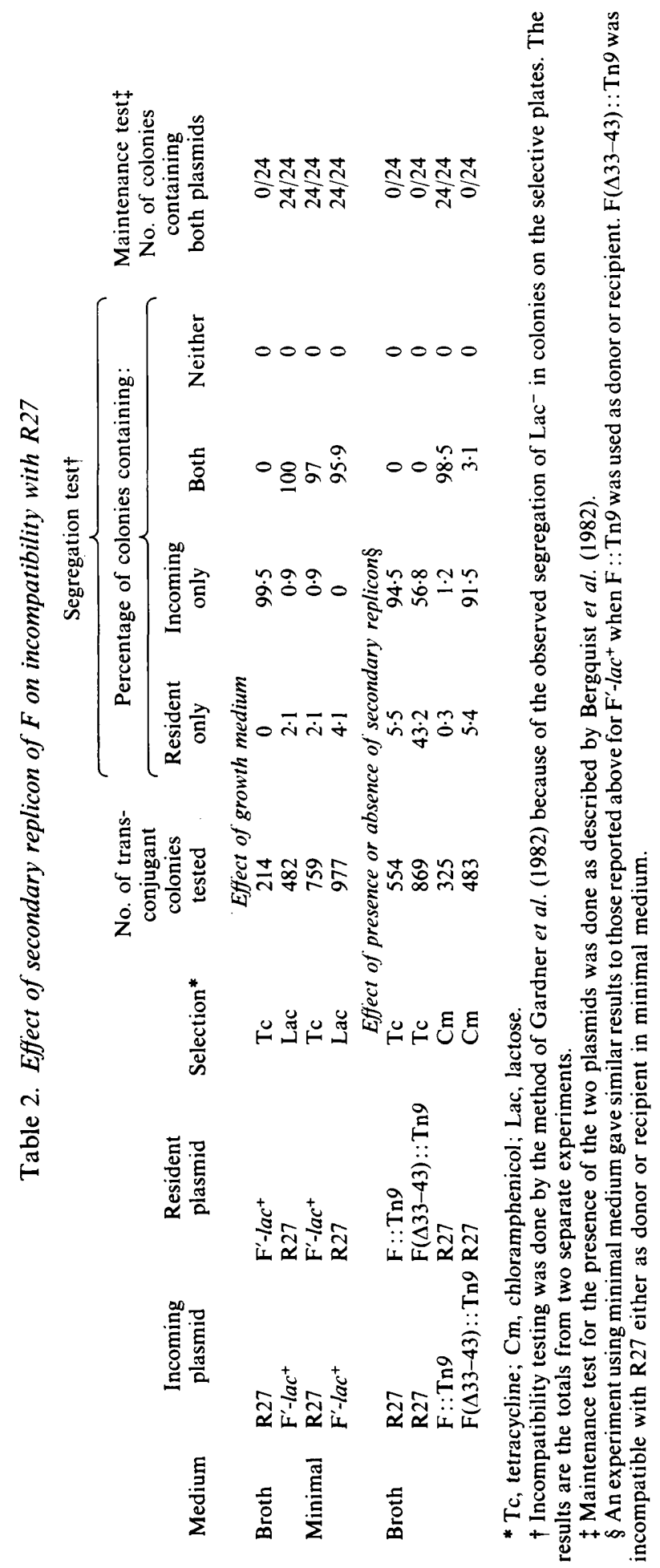


1982). $\mathrm{R} 27$ and $\mathrm{F}(\Delta 33-43):: \mathrm{Tn} 9$ were completely incompatible in both directions in the plasmid maintenance test, and hence $\mathrm{F}(\Delta 33-43)$ was indistinguishable from an $\mathrm{IncH} 1$ plasmid in this test.

That the $\mathrm{f} 5$ and $\mathrm{f} 7$ regions of $\mathrm{F}$ were the only ones involved in this incompatibility behaviour has been demonstrated by experiments in which cells carrying cloned f5 (pML31; Lovett \& Helinski, 1976) and f5f7 (Lane \& Gardner, 1979) fragments were used in similar incompatibility tests with R27. The incompatibility behaviour of the miniplasmids was identical with that of the entire plasmids (data not shown).

\section{Interpretation of incompatibility tests}

The incompatibility results reported above suggested that when $\mathrm{F}$ was the resident plasmid, entry of R27 resulted in a shift to replication from the secondary replicon. The two plasmids appeared to be incompatible unless minimal medium was used for growth. $F(\Delta 33-43)$ did not have the option of using the secondary replicon and segregated when R27 entered. We suggest that the secondary replicon was used for replication by wild-type $F$ when it was the entering plasmid, so that replication of $R 27$ was not prevented, but $F(\Delta 33-43)$ must use the primary replicon. It appeared that the region of homology in $\mathrm{R} 27$ had an essential role in the replication of that plasmid even though the fragment, on its own, was not a replicon (P. L. Bergquist, unpublished observation).

The one-way incompatibility behaviour of $\mathrm{F}$ and $\mathrm{IncH} 1$ plasmids has similarities to the phenomenon of dislodgement described for R394 (IncT) and Plac-R447b with plasmids from incompatibility group N (Coetzee et al., 1972, 1975). Dislodgement may result in either the complete elimination of the resident plasmid, loss of some of the phenotypic characters of the resident, or recombination between the two plasmids. Thus far, all plasmids susceptible to dislodgement carry DNA sequences homologous to N plasmids. Coetzee et al. (1975) concluded that $\mathrm{N}$ group plasmids produced a nuclease which recognized N DNA exclusively. On entry of the plasmid into a cell, the target for the nuclease was a fragment of DNA carrying kanamycin resistance from $\mathrm{R} 447 \mathrm{~b}$ inserted into the resident $\mathrm{A}-\mathrm{C}$ group plasmid, $\mathrm{P}$ lac. The $\mathrm{N}$-group specific nuclease was postulated to be repressed after the establishment of the IncN plasmid in the cell.

An interaction of this nature, involving the degradation of a plasmid carrying a specific fragment of DNA, would be difficult to distinguish from an incompatibility reaction. We believe that IncN-plasmid type dislodgement was not involved in the phenomenon we have described. F and the IncN plasmid R447b are completely compatible and no homology could be detected between the $f 5$ and $f 7$ regions of $F$ and R447b (P. L. Bergquist, unpublished observation). It is more difficult to exclude the possibility of a nuclease coded for by the region of the IncH plasmids that is homologous with $\mathrm{F}$. However, if this type of dislodgement reaction was occurring, it is difficult to explain the results showing that $\mathrm{R} 27$ and $\mathrm{F}^{\prime}-\mathrm{lac}^{+}$are compatible at slow growth rates (Table 2 ). If a transiently expressed nuclease was involved, the F DNA should have been attacked irrespective of the growth conditions.

The expression of the $E$ gene of $F$ appears to be subject to autoregulatory control (Kline \& Trawick, 1983; Søgaard-Andersen et al., 1984). It is tempting to speculate that the presumed protein from the homologous region of R27 could have a negative regulatory effect on E gene expression by binding to the putative operator sequence between inc $B$ and the E gene (SøgaardAndersen et al., 1984). However, the extent of the homology between the gene $\mathrm{E}$ coding sequence of $\mathrm{F}$ and the homologous region of the IncH 1 plasmids is not known. Heteroduplex analysis to define the extent of homology and examination of this homology by sequence analysis are obvious ways to resolve this question.

This research was supported in part by grants from the Medical Research Council of New Zealand and the University of Auckland Research Grants Fund (to P. L. B.) and from the Medical Research Council of Canada (to D. E. T.). P. L. B. thanks Dr Barrie Davidson, Biochemistry Department, Melbourne University, for computer facilities, and Anne Lock and Linda Malcolm for capable technical assistance. 


\section{REFERENCES}

Anthony, W. M., Deonier, R. C., Lee, H.-J., Hu, S., Ohtsubo, E. \& Davidson, N. (1974). Electron microscope heteroduplex studies of sequence relations among plasmids of Escherichia coli. IX. Notes on the deletion mutant of F, F $\Delta(33-43)$. Journal of Molecular Biology 89, 647-650.

Bergquist, P. L., Lane, H. E. D., Malcolm, L. \& DownARD, R. A. (1982). Molecular homology and incompatibility in the IncFI plasmid group. Journal of General Microbiology 128, 223-238.

Chabbert, Y. A. \& Gerbaud, G. R. (1974). Surveillance épidémiologique des plasmides résponsables de la résistance au chloramphénicol de Salmonella typhi. Annales de Microbiologie 125A, 153-166.

Coetzee, J. N., Datta, N. \& Hedges, R. W. (1972). R factors from Proteus rettgeri. Journal of General Microbiology 72, 543-552.

Coetzee, J. N., JacoB, A. E. \& Hedges, R. W. (1975). Susceptibility of a hybrid plasmid to excision of genetic material. Molecular and General Genetics 140, 7-14

Currier, T. C. \& Nester, E. W. (1976). Isolation of covalently closed circular DNA of high molecular weight from bacteria. Analytical Biochemistry 76, 431-441.

DatTa, N. \& Olarte, J. (1974). R factors in strains of Salmonella typhi and Shigella dysenteriae $\mathrm{I}$ isolated during epidemics in Mexico: classification by incompatibility. Antimicrobial Agents and Chemotherapy 5, 310-317.

Falkow, S., Guerry, P., Hedges, R. W. \& Datta, N. (1974). Polynucleotide sequence relationships among plasmids of the I compatibility complex. Journal of General Microbiology 85, 65-76.

Gardner, R. C., Caughey, P. A., Lane, D. \& BERGQUist, P. L. (1980). Replication mutants of the F-plasmid of Escherichia coli. II. Cloned replication regions of temperature-sensitive mutants. Plasmid 3, 179-192.

Gardner, R. C., Malcolm, L., Bergquist, P. L. \& LANE, H. E. D. (1982). IncD, a genetic locus in F responsible for incompatibility with several plasmids of the IncFI group. Molecular and General Genetics 188, 345-352.

Grindley, N. D. F., Grindley, J. N. \& ANDERSON, E. S. (1972). R factor incompatibility groups. Molecular and General Genetics 119, 287-297.

Hyman, R. W., Brunovskis, I. \& Summers, W. C. (1973). DNA base sequence homology between coliphages T7 and $\phi \mathrm{II}$ and between $\mathrm{T} 3$ and $\phi \mathrm{II}$ as determined by heteroduplex mapping in the electron microscope. Journal of Molecular Biology 77, 189196.

Kline, B. C. \& Trawick, J. (1983). Identification and characterization of a second copy number control gene in mini-F plasmids. Molecular and General Genetics 192, 408-415.

LANe, D. \& Gardner, R. C. (1979). Second EcoRI fragment of F capable of self-replication. Journal of Bacteriology 139, 141-151.

LANE, H. E. D. (1981). Replication and incompatibility of $\mathrm{F}$ and plasmids in the Inc-FI group. Plasmid 5, 100-126.

Lovett, M. A. \& Helinski, D. (1976). Method for the isolation of the replication region of a bacterial replicon: construction of a mini- $\mathrm{F}^{\prime} \mathrm{km}$ plasmid. Journal of Bacteriology 127, 982-989.

Murotsu, T., Matsubara, K., Sugisahi, H. \& Takanami, M. (1981). Nine unique repeating sequences in a region essential for replication and incompatibility of the mini-F plasmid. Gene 15, 257271.

Rigby, P. W. J., Dieckmann, M., Rhodes, C. \& Berg, P. (1977). Labelling deoxyribonucleic acid to high specific activity in vitro by nick-translation with DNA polymerase I. Journal of Molecular Biology 113, 237-251.

Roussel, A. F. \& ChabBert, Y. A. (1978). Taxonomy and epidemiology of Gram-negative bacterial plasmids studied by DNA-DNA filter hybridization in formamide. Journal of General Microbiology 104, 269-276.

Smith, H. R., Grindley, N. D. F., Humphreys, G. O. \& ANDERSON, E. S. (1973). Interactions of group H resistance factors with the $F$ factor. Journal of Bacteriology 115, 623-628.

SøgaARd-Andersen, L., Rokeach, L. A. \& Molin, S. (1984). Regulated expression of a gene important for replication of plasmid $\mathrm{F}$ in E. coli. EMBO Journal 3, 257-262.

TAYLOR, D. E. (1983). Transfer-defective and tetracycline sensitive mutants of the incompatibility group HI plasmid R27 generated by insertion of transposon 7. Plasmid 9, 227-239.

Watson, L. A., Phua, S.-H., Bergquist, P. L. \& Lane, H. E. D. (1982). An $M_{r} 29,000$ protein is essential for mini-F maintenance in E. coli. Gene 19, 173-178. 